\title{
HOE KAN SURINAME'S LANDBOUW TOT ONTWIKKELING KOMEN?
}

DOOR

\section{J. BOONACKER}

Om te beginnen moet ik een aanvulling geven op mijn artikel, geplaatst in het Februarinummer van dit jaar. Het artikel is nl. wat lang in portefeuille gebleven. In dien tusschentijd zijn er in de wijze van steungeving voor de koffie eenige belangrijke veranderingen gebracht. Met het gevolg dat daarvan thans op ruimer schaal wordt gebruik gemaakt dan aanvankelijk het geval was. En inmiddels heeft een plantage als suikeronderneming opgehouden te bestaan en verwerkt een andere suikeronderneming haar laatsten snit. Naar alle waarschijnlijkheid zullen binnenkort dus nog slechts twee suikerplantages in Suriname overblijven. Een verschil met het naastgelegen en een gelijk klimaat en gelijksoortige bodemgesteldheid bezittend Britsch-Guyana of Demerara, waar nog vierentwintig suikerplantages met een beplante oppervlakte van 21.000 H.A. bestaan.

Vergelijkt men den landbouw in Suriname, en dan zoowel den grooten als den kleinen, met dien in andere tropengebieden, dan valt het op, dat bevloeiing in Suriname zoo weinig toepassing vindt. Bijna alle gewassen lijden in Suriname door dat gemis aan bevloeiing. Ten gevolge van herhaaldelijk optredende perioden van abnormaal-scherpe droogte bestaat er weinig zekerheid omtrent productie en worden goede oogsten veelvuldig afgewisseld door onvoldoende oogsten. Zoowel de suikercultuur als de koffiecultuur ondervinden dit nadeel. Maar in nog sterkere mate de cultuur van citrusvruchten, waarbij door een scherpe droogteperiode de productie gedurende eenige jaren achtereen in de war kan worden gestuurd. Door toepassing van bevloeiïng zou men ongetwijfeld grootere oogstzekerheid verkrijgen; de gemiddelde productie zou er door naar boven gaan en men zou tevens den oogsttijd meer in de hand hebben, wat bij vele cultures een factor van belang is. In jaren met betere conjunctuur - in tijden dus van hoogere prijzen voor de producten - komt het er minder op aan of 
men de hoogst mogelijke productie haalt, maar nu de prijzen laag zijn en zij naar alle waarschijnlijkheid langen tijd op betrekkelijk laag niveau zullen blijven, is het van belang de productie duurzaam op te voeren. Waar de gelegenheid daartoe gunstig is en het te verwachten is, dat de kosten voor den aanleg van bevloeiing ruimschoots zullen worden vergoed, zal men dus goed doen daartoe over te gaan. Voor den tropischen landbouw, die om de een of andere reden geen bevloeiïng kan toepassen is het bestaan onder de tegenwoordige omstandigheden moeilijk en men zal hem niet anders dan met kunstmiddelen (voorschotten, subsidies enz.) in het leven kunnen houden.

Ondervindt de landbouw in Suriname aan den eenen kant als bezwaar het gemis van bevloeiïng, aan den anderen kant is het systeem van ontwatering, sedert eeuwen in gebruik, onder de tegenwoordige omstandigheden niet meer voldoende. In Suriname wordt nl. in het lage polderland, waar de groote landbouw uitsluitend en de kleine landbouw gedeeltelijk is geconcentreerd, algemeen gebruik gemaakt van natuurlijke loozing door sluizen op rivieren en stroomen. Dit beperkt de loozingsmogelijkheid tot een betrekkelijk geringe, met het laagste buitenwater verband houdende diepte beneden het maaiveld, een diepte, die voor den zwaren kleibodem volstrekt onvoldoende is om een diepen bouwkruin te vormen. De bouwkruin is in het Surinaamsch polderland dan ook opvallend ondiep, voor alle cultures en niet in het minst voor boomcultures zeker een op den duur zeer ongunstige omstandigheid. In een ondiepen bouwkruin heeft diepe grondbewerking geen reden van bestaan, ja veelal brengt het, alleen op den langen duur, te herstellen nadeelen mede. Hetgeen men indertijd heeft ondervonden bij de bacovencultuur, toen diepe omwerking van den bodem werd voorgeschreven met het gevolg, dat in heel veel gevallen door het bovenbrengen van slechten ondergrond de velden voor langen tijd in cultuurwaarde werden achteruit gezet. Een dieperen bouwkruin zal men op den duur alleen dan kunnen krijgen als de natuurlijke loozing wordt bijgestaan door bemaling.

Aan bovengenoemde twee voorwaarden, bevloeiïng en bemaling, moet naar inzicht van schrijver dezes in de eerste plaats worden voldaan om de bestaande cultuurmogelijkheden in het polderland van Suriname meer dan nu het geval is te benutten. Kleine plantages zullen niet in staat zijn zich hiervoor belangrijke uitgaven te getroosten. Dat kunnen uit een finantieel oogpunt alleen grootere ondernemingen doen. Kleine plantages hebben in 
het laagland van Suriname dan ook feitelijk geen recht van be-

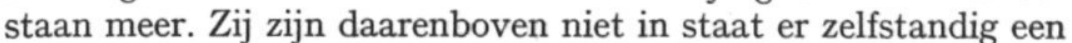
behoorlijke inrichting tot verwerking van het product op na te houden. De kleine ondernemingen moeten dus verdwijnen, tenzij men er in slaagt ze in grootere coöperaties bijeen te brengen. Ook de kleine landbouw heeft op zichzelf staande in het lage polderland weinig reden van bestaan. De eenling is nauwelijks in staat waterkeerende dammen aan te leggen en in behoorlijken toestand te onderhouden en de noodige duurzame loozingswerken op te richten. Alleen in grootere polders op coöperatieven grondslag vereenigd zullen zij in moeilijke tijden het hoofd boven water kunnen houden.

Het bevloeiïngsvraagstuk is voor het lage alluviale land van Suriname ongetwijfeld moeilijk op te lossen. Maar er zijn gedeelten, waar aan bevloeiïng niet zooveel moeilijkheden in den weg staan en het zijn die gedeelten, waarheen onze blik zich richt als centra van landbouw voor de toekomst. Het is jammer, dat vele der bestaande ondernemingen niet in die gedeelten liggen. Hun toekomst zou er thans beter uitzien. Nu kan men niet anders verwachten dan dat ze op den duur in rijstlanden zullen worden omgezet, omdat de groote regentijd in den regel voldoende water geeft om althans één rijstoogst tot rijpheid te brengen, terwijl de ondiepe bouwkruin met overigens slecht doorlatenden ondergrond factoren zijn, die de cultuur van rijst niet in den weg staan. De suikerplantage Rust en Werk wordt reeds in dezen geest omgezet. In de andere seizoenen zal men het land in hoofdzaak dienstbaar kunnen maken aan de veeteelt en op kleine schaal aan den verbouw van tweede gewassen, aan de teelt waarvan evenwel wegens het gemis aan bevloeiïng veel risico zal blijven kleven.

In Britsch Guyana is bemaling op bijna alle suikerplantages gebruikelijk en heeft men ook aan het vraagstuk van bevloeiing meer aandacht geschonken, zoodat de grootere ondernemingen vrijwel alle in het genot zijn van een behoorlijke bevloeiïng. Bij enkele van die ondernemingen is men er tevens in geslaagd met gunstig resultaat diepere mechanische grondbewerking door kabeltractie toe te passen met het gevolg, dat die ondernemingen de laatste jaren hun opbrengst hebben kunnen opvoeren tot gemiddeld boven 3.000 K.G. suiker per akker over een groot areaal. Ik geloof niet dat men in Suriname, waar de bodem van betere hoedanigheid is, op een gelijke productie gedurende een reeks van jaren achtereen kan wijzen.

Resumeerende geef ik dus als mijne meening, dat in de lage

West-Indische Gids XIV 


\section{ONTWIKKELING VAN SURINAME'S LANDBOUW}

kleilanden van Suriname's alluviaal gebied onder de tegenwoordige omstandigheden landbouw met uitzondering dan van de cultuur van rijst annex veeteelt slechts met kans op oeconomisch resultaat mogelijk is op groote ondernemingen, waar bevloeiing en bemaling worden toegepast eventueel en voor zooveel noodig gepaard aan moderne mechanische grondbewerking en waar het product wordt verwerkt, indien productverwerking een onderdeel van het bedrijf uitmaakt, in technisch goed in elkaar zittende en oeconomisch werkende inrichtingen. Kleine plantagebedrijven en op zichzelf staande kleinlandbouwbedrijfjes zullen bij een conjunctuur als de tegenwoordige in die streken nimmer kunnen rendeeren. Waar het verouderd plantagebedrijf in Suriname niet in den geest als hiervoren geschetst op meer moderne leest kan worden geschoeid zal het gedoemd zijn te verdwijnen en zullen nòch voorschotten en subsidies nòch invoering van nieuwe cultures het van den ondergang kunnen redden.

Daartegenover bestaat er geen enkele reden om aan te nemen, dat groote modern ingerichte landbouwondernemingen niet met andere landen zouden kunnen concurreeren waar het gewassen betreft, welke getoond hebben op den Surinaamschen kleigrond goed te gedijen zooals suikerriet en koffie. Die grond is bij uitstek vruchtbaar en zal in productiecapaciteit zeker niet onderdoen voor den besten bodem in andere landen, mits aan grond en gewas de behandeling worde gegeven, die in staat is de productie tot het maximum op te voeren.

(Wordt vervolgd) 